\title{
Nuo Dance of Jiangxi: From the Community Dance to Ritual Significance in Catherine Bell's Model
}

\author{
Xiaoyu Yang1,2 \\ ${ }^{1}$ Roehampton University, London, UK \\ ${ }^{2}$ Beijing Sports University, Beijing, China \\ Email: xiaomianmian2017@163.com
}

How to cite this paper: Yang, X.Y. (2018) Nuo Dance of Jiangxi: From the Community Dance to Ritual Significance in Catherine Bell's Model. Open Journal of Social Sciences, 6, 249-257. https://doi.org/10.4236/jss.2018.611018

Received: October 21, 2018

Accepted: November 20, 2018

Published: November 23, 2018

Copyright $\odot 2018$ by author and Scientific Research Publishing Inc. This work is licensed under the Creative Commons Attribution International License (CC BY 4.0).

http://creativecommons.org/licenses/by/4.0/

\section{c) (i) Open Access}

\begin{abstract}
The study focuses on the ritual phenomena in the traditional local Chinese community dance Nuo in Jiangxi, China. Catherine Bell's (1953-2008) model for ritual theory and ritual Practices is applied to this study, as she starts her career from a study of Chinese local Taoist religion and ritual studies. Nuo Dance is a popular form of primitive community dance in Jiangxi Province, China, as its religious ritual features are significant.
\end{abstract}

\section{Keywords}

Nuo Dance, Ritual, Community

\section{Introduction}

This paper discusses ritual dance, as well as special events in community movements and dancing. The study will focus on the ritual phenomena in the traditional local Chinese community dance Nuo in Jiangxi, China. Catherine Bell's (1953-2008) model for ritual theory and ritual Practices will be applied to this study, as she starts her career from a study of Chinese local Taoist religion and ritual studies [1].

The major question of this study will address how the dance Nuo is used as a ritual in local Chinese traditional customs, rather than simply the art of performance like the modern dance. From the early days of human society to the primitive tribal culture that continue to today, dance is not only a natural revelation of extreme joy and sorrow, but also a part of the witchcraft and religious ritual, which is another early factor in the social development of the dance. Primitive 
dance is intended for witchcraft, divination and religious rituals in ancient China.

Ritual is the general term for formal activities that have religious or traditional symbolic meanings. People in different parts of the world use different vocabulary to express their ritual activities. That is to say, a certain number of people must come together to complete a symbolic event and jointly sense the same emotions. There must be a regular procedure. In the ancient Chinese cultural practices, they refer not only to religious cults and funeral ceremonies, but also applicable to conquests, weddings, funerals, occupations, habits, etc [2].

Bell [3] correctly notes that, in the course of religious studies, people have a lot of interest in the appreciation of the ritual ceremonies, as the primitive religion is inseparable from the ritual, and many ceremonies need to sing and dance. Useful analysis of many ceremonies is the premise of Anthropology and sociology, which is often not understood by religious researchers, and is regarded by some people as theological problems [3].

Now that Bell's work on ritual theories has received a great deal of attention, in the space allocated here, this paper would like to include these topics and draw inspiration from her different aspects. Some of her article about dance and religious rituals in China, have inspired the title of this article. One of the topics has recurred, which is the relationship between Chinese dance and religious rituals. Bell [4] notes that dance is an obvious way to promote the transmission of religious thoughts, but she also points out how modern dance can make religious traditions weakened. Bell's work on Chinese religion and ritual is certainly not an alien topic among scholars, but the ritual issue in choreography and dance has not attracted enough attention from religious scholars, and is causing problems in the study of other larger religious fields.

\section{Literature Review}

Scholars who study Chinese religious beliefs mostly use folk beliefs, rituals, and symbols as identities of certain social groups [5]. Bell [3] places rituals in a very important position, almost independent of religion. Bell [4] prefers to use the word Ritual alone rather than religion. She believes that ritual is a better word in Chinese context, and religion is a modern Western term and often useless for many Asian or local community religions [4]. In her ritual theory and practice, she claims that her interests in rituals began with her doctoral dissertation on Chinese Taoist research, and she proposes key methodologies that helps advance the issue in the field. Bell's [6] works on Chinese Taoist ritual ceremonies and the more widespread indigenous religions in China have opened up new lines of study.

Bell [3] believes that China has not formed a formatted religion for a long time of history, but it attaches great importance to rituals. Local religions exhibit complex interactions at any level of ritual life, including the local level of rural religion and rituals, where dancing is an integral part. This level covers but transcends family and pedigree practice. Catherine Bell [7] believes that these dis- 
tinctions are all signs that religion is considered as a boundary between different social communities, and different levels.

Bell's ritual study is developed from Victor Turner [8], who divides the ritual into two categories, the life-crisis rituals and rituals of affliction. The former refers to the transitional ceremony of life, and the latter is a ritual to reduce the impact of the holy penalties. These two categories emphasize the nature of ritual community and Turner's views on the social cultural function of rites. In talking about the ritual process, Turner [8] inspects the Zambia Ndembu ceremony and the development of his concept Communitas. He uses it as a purely interpersonal relationship that transcends any structural form. Since 1969, Turner has demonstrated how to use ritual behavior and symbolic analysis as the key to understanding the social structure and process [9].

Starting from Turner's divisions, Bell distinguishes six types of rituals related to community-based traditions and beliefs: rites of transition, calendar, exchange and sharing, ritual of disaster reduction, banquets, fasting and festival ceremonies, and political ceremonies. According to Bell, in these six kinds of frameworks, the customary cognitive model of ritual is generally maintained, that is, the relationship with belief and religious tradition, which basically embodies the core values of anthropological ritual [10].

Catherine Bell [4] refuses to narrow down ritual with any definition. Instead, her purpose is to reveal how definitions emerge and evolve and to help us become more familiar with the interplay of tradition, exigency, and self-expression that goes into constructing this complex social medium. According to LaMothe [11], Bell provides an historical survey of ritual theories in her book about rituals. Key to her definition is that ritual is a complex socio-cultural medium that is chosen to invoke ordered relationships between human and non-immediate sources of power, authority, and value via an expression of gestures and words.

In her view about dances, Bell [3] notes that in primitive tribes, the original purpose of dancing is not to be seen or applauded by the audience, but a ritual to the gods. Some even perform ritual under secret conditions. In this sense, Nuo dance emerged as a form of comfort and pray, can resonate with the heaven and earth. Among the Nuo dances and their masks, there are both respect for the gods of the Heaven, contempt for the ghosts of hell, admiration for the ancestors, deification of the legend of generals and ministers, deception of the fainting emperors, and various factors. They mix up miscellaneous feelings together [12].

The debate around social participation is discussed around the current ideological and political background. Dance is usually a recurring feature in ritual practice. Modules can also help us understand human nature through performance and mediation, and the threshold of what concept may mean [3].

\section{Basic Module Application}

This thesis uses Bell's ritual theory and ritual practice model, and takes the community dance Nuo as an example to conduct a preliminary discussion of the practice module, and place the dance in the category of religious rituals. Due to 
limited space, there is not enough room for the description of the artistic value and details of Nuo dance itself. The paper discusses the practice of Nuo rituals. It shows people's dance ideology and body boundaries. Whether in the context of a ritual or community dance, what is the purpose of answering the dance, who is organizing and who is dancing? Who includes or excludes? Does the dancers involve in politics or increase social cohesion? Whether it has got encouraged or suppressed.

This module provides a broader approach to discussing dance in the spiritual and cultural context. As Bell [4] notes, dance is often a recurring feature of ritual practice. This module also helps to understand tribal culture through performances and ceremonies. Although Bell [6] conducts research on Taoist rituals in China, and there is a close connection between erotic dance and Taoism, Bell and other scholars do not conduct more in-depth research on the meaning of Nuo dance. Module debate is a matter of morality and ritual. It also uses the theory and methods of anthropology, sociology, community dance, and performance studies [13], to analyze the symbolism of the masks of dancers and their props or masks. Strictly speaking, this is not a pure dance technique paper, but a study aimed at studying how the local community uses traditional community dance to achieve religious rituals.

\section{Ritual Significance of Dance Nuo}

\subsection{Definition of Nuo Dance}

Nuo Dance is the main performances of Jiangxi Nuo, known as Chinese dance living fossil. Which musical accompaniment is generally simple, drums, gongs and percussion. The performance of NuoNuo dance group called Nuo class members generally have eight to more than ten people, often have strict rules. Appear often in NuoNuo dance during the ceremony climax and performance stage, around which the program is rich, has double effects of sacrifice and entertainment.

When it comes to Nuo, we have to talk about the witch. Nuo can be regarded as a kind of witch, if it is to refer to the form and consciousness of the primitive religion with the witch. But in fact, the witch was originally a kind of primitive religion with specific connotation. Both Nuo and witch were different in terms of function and structure. Nuo is the main function of offering Li God, drive the epidemic; and the witch function is mainly for rain.

Tracing the origin of Chinese dance, the ancient witchcraft sacrificial dance not only became the main body of primitive dance at that time, but its development had important significance for the folk dance of the later generations. Under the power of primitive religious beliefs, although sacrificial ritual dance can not be regarded as an artistic aesthetic activity, for tribal members, this kind of ritual sacrificial dance is an idol of beauty. On the one hand, it has members of the unity clan and a total of them. The positive significance of nephews, on the other hand, has become a spiritual pillar that encourages community groups to 
fight against nature. These two major functions have objectively promoted the development of human aesthetic consciousness and gradually enabled dance art, the human spirit production, to embark on the course of development [7].

As Bell [3] observes rightly, China has the most developed and complex ritual system at different levels to communicate with heaven and earth. Chinese traditional ritual culture is a top-bottom ranking and strict system of etiquette. The emperor represents the Heaven and the common people stand for the Earth. There is a certain connection between the form of the lower level folk religion and the more organized national and royal level, but the difference and chasm are huge. The highest level of official religious ritual is the Emperor's ritual ceremonial offering to the Heaven, which is an effective way to prove its legitimacy and divine endowment. The village squire is also keen on witchcraft ceremonies, is also the way to influence. Official and folk religions learn from each other in many ways, and local religions also absorb many official ceremonies. In practice, the official ceremony system based on the order of heaven and earth can create spaces for the mean ghosts for the rural areas at the bottom of Gods' halls [6].

At the same time, Bell [7] notes that the official system ceaselessly tried to control the ritual practice in which the countryside was communicated with the heaven, because communication with heaven was the patent of the emperor, and the people of the countryside could only communicate with the ghosts in the underground hell, and in the masks of the dance, most of them were ugly and dirty looking. The local worship rites, including the media they used, and the level of the gods or demons, might violate the proper hierarchy of communication with God. The presumption is that the rural witchcraft ceremony if unchecked, could threaten the emperors' privileges to reach the Heaven. In a comprehensive analysis of the ritual life of China in the early nineteenth Century, Bell [3] find that all forms of ritual practice occupied every corner of the social structure, periodically overlapping or polarizing (Bell, 1997). It is ironic that the more societies fall apart, and far more prosperous folk witchcraft rituals and dance [14].

\subsection{Nuo Mask}

The Nuo exorcise dance is a popular sacrificial dance in the Yangtze River Basin since ancient times in China. The exorcism dance, originated from the ancient sacrificial rites, for thanksgiving prayer to fathers, Exorcism of evil spirits, full of strong religious color. From the perspective of art genesis, it combines music, dance and poetry together to form an integrated art form. The prototype of dance is Nuo sacrifice rites. Among its many props, Nuo mask is one of the important characteristics of art [15] (Figure 1).

Nuo dance masks are their typical props, as a special form of ritual expression, and also an important feature of Nuo dance from other dramas. For the exorcise mask, the name of the exorcise mask, the choice of material, the size ruling, the color of the paint, the utilitarianism and the way of wearing it, because of the difference of region, nationality, culture and aesthetics, it is varied and colorful. 
The material of the mask is metal, jade, shell, animal tooth, bronze, wood, bark, nut shell, gourd, fur, bamboo strips, pulp and pottery. Most of Nuo masks are the characters of human and animal combinations with different colors to show tokens like shrew, ferocious, powerful, amiable, gentle, beautiful, loyal, and slippery, to stand for the God of the mountain, the road, the commander and so on. These deformed, stylized and imaginative images make people feel shocked [16].

Nuo mask is the product of totem worship and primitive religious worship to gods. The Nuo dance programs in Jiangxi, including Wuyuan and Nanfeng regions, are mostly based on myths and folklore stories. In the performing dancing, they still retain the unique style of simplicity, rough, concise, exaggerated. Most of the movements are going on crutches, knees, sinks, chest and abdomen. The music accompaniment is composed of three parts, percussion, melody and singing. The old villagers treat Nuo masks as spirits themselves, must hold worship ceremonies for opening the cabinet, wearing, performing, and sealing. They choose the best timing and auspicious occasion to have the ceremony, otherwise, it is thought to bring bad luck. In the process of this instrument, Nuo master will play drums, and preside over the ceremony. Dancers wear masks, disguise themselves as an imaginary, ferocious exorcise, with a strong rhythmic drumstick and a frenzied dance to exorcise [7] (Figure 2).

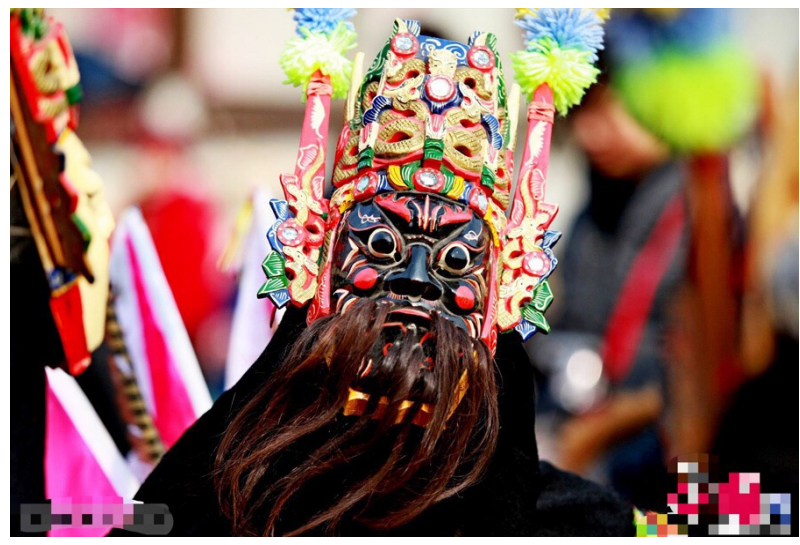

Figure 1. Nuo dance mask. China network picture, photo by Din Wei, [16].

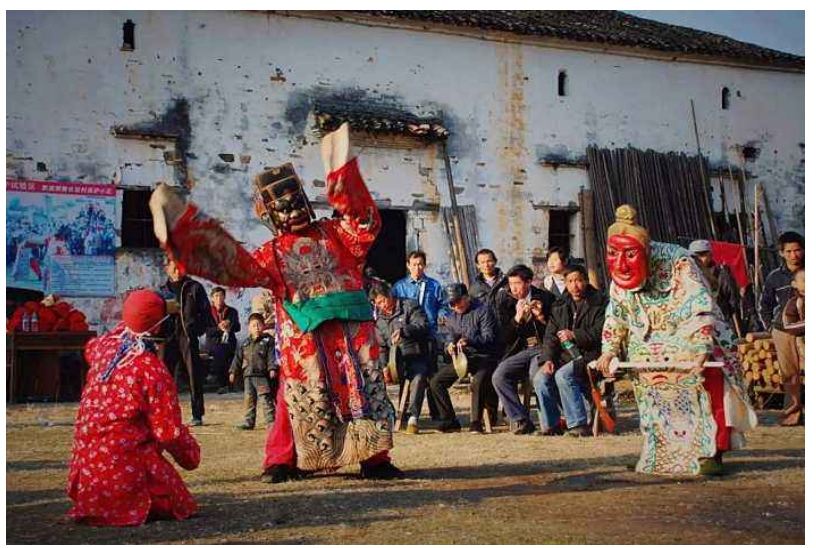

Figure 2. Nuo Dance in Jiangxi, Photo: Xin DeCheng [17]. 


\subsection{The Main Characteristics of Nuo Dance}

There is a nexus in the Nuo dance: the hair is angry, the head shaking, the shoulders trembling, the hands and feet dancing along one side, the speed and the rhythm urgent, and every move must step on the drum. It is summed up mainly in the four visual features, namely, the masks, stride steps, music rhythms, and facial decoration. It is believed that the exorcise masks directly shortens the distance between man and God in the performance of exorcise dance, makes the spiritual believers get great comfort and consolation in the mind, thus fitting the Bell's ritual category of appeasing and appealing [4].

Nuo dance is a unique style, eye-catching appearance dance team. The exorcism dance performance form has two kinds: one is a person as the goddess of mercy in the way, followed by six men with six distinctive costume dances while drumming, they respectively represent two masks, Fu Lushou joy, all six immortals. The four immortals shoulder the burden of a head is a cotton blanket, head drum. Blanket or flat, safe meaning; drum and Valley is a homonym, as a bumper grain harvest.This six side beat Muyu, drum, ruler, plate and other props, the majestic music ensemble.

The dance like horse, swing boxing, jumping, lunges, sometimes interspersed with rolling, pyramid, typesetting and other movements, showing rough fierce in the strong rhythm of drums in the majestic. Behind is a man carrying hundreds of umbrellas and hundreds of umbrellas for God. The hundred umbrellas were stitched by the girls and the new daughter-in-law. The cloth was embroidered with the names of the heads of each household and the auspicious words. After 100 followed the six immortals umbrella, umbrella should be along with the music kept turning umbrella, and the whirling and jumping, performing a variety of dance movements.

Exorcise is the basic form of Nuo. Jiangxi Nuo ceremony followed the ancient ritual, a Nuo (out of the box, out of the hole, a case), play (jump, jump, NuoNuo, ghost dance), drivenuo (search division, sweep, Jing), Nuo (round sealing, sealing holes and other basic applications received). The time usually begins in the 1th day of the first month of the Chinese lunar calendar and ends a few days after the Lantern Festival (a few Nuo classes end in February). Exorcise exorcise is the focus of the whole ceremony.

Bell [4] has not conducted any study on Nuo dance specifically, why people dance with masks or not, where is the difference between masks and dancing? According to her plan, she supposes to find better tools in the future to know what people are doing when they bow, burn incense to the gods, wear masks and dance in the square, or explain the meaning of the rituals. However, all these dance behaviors are the way to deal with the external environment and the power and strength they perceive. They use different interpretations and different ranges. Modern people should not lightly refute or think of backward and unnecessary programs [18]. 


\section{Conclusion}

Through the above analysis, it is obvious; Nuo dance has more ritual significance than performing art value in modern terms. In the past, the study of the Nuodance and drama of exorcism is basically intended to collect its folk culture and intangible cultural heritage, and ignore the religious significance of its religious rites. Nuo dance of Jiangxi, China, is more representative of the ritual ceremony in the form. Through the application of Bell's ritual theory to the investigation of Nuo dance, this paper finds that Nuo has a certain religious ritual meaning and has a strong connotation of community activities, especially it is of great significance to the cohesion of rural community identity.

\section{Conflicts of Interest}

The author declares no conflicts of interest regarding the publication of this paper.

\section{References}

[1] Aslan, R. (2009) Foreword, in Bell, C. (2009) Ritual: Perspectives and Dimensions. Oxford University Press, Oxford, vii-viii.

[2] Hughes-Freeland, F. (1998) Ritual, Performance, Media. Routledge, Abingdon-onThames, 21-33.

[3] Bell, C. (1997) Ritual: Perspectives and Dimensions. Oxford University Press, Oxford, 123-141.

[4] Bell, C.M. and Benney, A. (2002) Interview by Alfred Benney, Catherine Bell Engages with the Question: How Do You Define Religion? Digital Commons. http://digitalcommons.fairfield.edu/asrvideos/82

[5] Brashier, K.E. (2011) Ancestral Memory in Early China. Harvard Yenching Institute, Cambridge, 4-16. https://doi.org/10.2307/j.ctt1dnnb5m

[6] Bell, C. (1988) Ritualization of Texts and Textualization of Ritual in the Codification of Taoist Liturgy. History of Religions, 27, 367-393. https://doi.org/10.1086/463128

[7] Bell, C. (1992) Ritual Theory, Ritual Practice. Oxford University Press, Oxford, $10-15$.

[8] Turner, V. (1969) Liminality and Communitas. In: The Ritual Process: Structure and Anti Structure, Cornell University Press, Ithaca, 41-49.

[9] Grimes, R. (1982) Beginnings in Ritual Studies. University Press of America, Lanham, 25-31.

[10] Turner, V. and Abrahams, R. (1996) The Ritual Process: Structure and Anti-Structure (Lewis Henry Morgan Lectures 1969). Routledge, Abingdon-on-Thames, 12-29.

[11] La Mothe, K.L. (2015) Why We Dance: A Philosophy of Bodily Becoming. Columbia University Press, New York City, 15-19.

[12] Dean, K. (1993) Taoist Ritual and the Popular Cults of South-East China. Princeton University Press, Princeton, 173-186.

[13] Houston, S. (2005) Participation in Community Dance: The Road to Empowerment and Transformation? New Theatre Quarterly, 21, 167-178.

https://doi.org/10.1017/S0266464X05000072 
[14] Robson, J. (2012) Brushes with Some Dirty Truths, Handwritten Manuscripts and Religion in China. History of Religions, 51, 317-343. https://doi.org/10.1086/664721

[15] Choi, M. (2017) Death Rituals and Politics in Northern Song China. Oxford University Press, Oxford, 33-54. https://doi.org/10.1093/oso/9780190459765.001.0001

[16] Huang, X. and Hu, J. (2000) Dance Festival: The Guangxi Folk Ritual Dance and Cultural Field Trips and Research (Chinese Edition). Guangxi Normal University Press, Guilin, 65-69.

[17] Wang, Z. (2013) Alive Memories: Wuyuan Intangible Cultural Heritage List One (Huiju, Nuo Dance, Tea Ceremony), (Chinese Ed.). Jiangxi Peoples Publishing House, Nanchang, 78-86.

[18] Schechner, R. (1993) The Future of Ritual: Writings on Culture and Performance. Routledge, Abingdon-on-Thames, 34-56. https://doi.org/10.4324/9780203359150 